\title{
Escolha Profissional e Inserção no Mercado de Trabalho: Percepções de Estudantes Formandos
}

\author{
Satisfação profissional de formandos
}

\author{
Marúcia Bardagi \\ Maria Célia Pacheco Lassance \\ Ângela Carina Paradiso \\ loneide Almeida de Menezes
}

\section{Resumo}

A partir da carência de estudos avaliando as necessidades dos formandos no país, esta pesquisa investigou a satisfação com a escolha profissional e as expectativas quanto à entrada no mundo do trabalho em 340 formandos da Universidade Federal do Rio Grande do Sul. Os alunos, de ambos os sexos $(M=25$ anos; $D P=5,35)$, responderam a um questionário de 18 itens elaborado para o estudo. A maioria $(53,1 \%)$ relatou estar satisfeita com a própria escolha profissional. $O$ descontentamento com o mercado de trabalho foi um fator importante para a insatisfação com a escolha, enquanto a identificação pessoal mostrou-se relacionada à satisfação. A maioria dos participantes relatou interesse por orientação profissional, tendo enfatizado a instrumentalização para a procura de emprego. Estes resultados demonstram a insegurança dos alunos quanto ao início da atividade profissional e a necessidade de intervenções específicas na área vocacional para o público universitário, focalizando a transição universidade-trabalho.

Palavras-chave: Mercado de trabalho; Universidade; Orientação profissional

\section{Career choice and insertion in labor market: perceptions from college seniors}

\begin{abstract}
Since there is a lack of knowledge about needs of university students in Brazil, especially of those concluding undergraduation, this study investigated satisfaction with career choice and needs for Professional Guidance processes in a sample of 340 students of Rio Grande do Sul Federal University. Students of both sexes $(M=25$ years; $S D=5,35)$ answered an I8-item questionnaire constructed for this survey. The majority of students $(53,1 \%)$ is satisfied with their professional choices. Disappointment at labor market opportunities was related to career choice frustration, and personal identification was related to satisfaction. Most of the participants reported need for professional guidance processes, especially skills for job search. This results show how insecurity undergraduates are towards the beginning of professional activities and the need for specific vocational interventions with this public concerning the university-work transition.
\end{abstract}

Keyword: Workplace; University; Theorical orientation

\section{Elección profesional e inclusión en el mercado de trabajo: percepciones de estudiantes no recibidos}

\section{Resumen}

A partir de la falta de estudios evaluando las necesidades de los estudiantes todavía no recibidos en el país, este trabajo ha investigado la satisfacción con la elección profesional y las expectativas en relación a la inserción en el mundo del trabajo en 340 estudiantes de la Universidade Federal do Rio Grande do Sul. Los alumnos, de ambos sexos $(M=25$ años; $D P=5,35)$, han respondido a un cuestionario de 18 ítems hecho para el estudio. La mayoría $(53,1 \%)$ ha relatado estar satisfecho con la elección de la profesión. El desagrado con el mercado de trabajo ha sido un factor importante para la insatisfacción con la elección, mientras que la identificación personal se ha mostrado relacionada a la satisfacción. La mayoría de los participantes ha relatado interés por la orientación profesional, y han destacado la instrumentalización para buscar trabajo. Estos resultados han demostrado la inseguridad de los alumnos en relación al comienzo de la actividad profesional y la necesidad de intervenciones específicas en el área vocacional para el público universitario, centrando la transición universidad-trabajo.

Palabras clave: Mercado de trabajo, Universidad; Orientación profesional 


\section{Introdução}

No decorrer do desenvolvimento vocacional, especialmente no sistema formativo brasileiro, a passagem pelo ensino superior é quase uma unanimidade nas expectativas dos adolescentes e adultos jovens. Especificamente, para os jovens das classes média e alta parece não existir outra forma de profissionalização ou inserção no mercado de trabalho (Soares, 2002). Pesquisas realizadas com adolescentes desempregados (Pizzinato, Boeckel, Dellazzana, Coral \& Sarriera, 200I), adolescentes de escolas públicas e privadas (Ribeiro, 2003; Sparta, 2003) mostram que freqüentar um curso superior são projetos definidos por indivíduos de diferentes culturas e classes sociais. A literatura brasileira da área da orientação profissional e de carreira, no entanto, tradicionalmente tem focalizado seus estudos na etapa da adolescência, na transição entre o ensino médio, conforme já sinalizava Uvaldo (1995) na década de 90, ao pesquisar artigos e livros na área. São poucos os estudos e intervenções que identificam fontes de satisfação com a escolha profissional e analisam trajetórias profissionais e comportamento vocacional entre estudantes universitários.

Satisfação profissional é um conceito multifacetado e engloba aspectos pessoais, vocacionais e contextuais da realidade do trabalho. Super, Savickas e Super (1996) definem que a satisfação profissional do indivíduo resulta da percepção de que o trabalho é uma expressão do seu autoconceito, ou seja, de que é possível, através do exercício profissional, expressar os próprios valores, interesses e características de personalidade. Nesse sentido, em um contexto de formação profissional como o período universitário, satisfação pode ser entendida como um sentimento de identificação, ajustamento à área de formação em termos de bem-estar e comprometimento.

O estudo de Pachane (2004), por exemplo, avalia a percepção dos alunos acerca do impacto da universidade sobre seu desenvolvimento pessoal e aponta como aspectos relacionados à satisfação os relacionamentos pessoais $(40,22 \%)$, a aprendizagem ( $1 \mathrm{I}, 73 \%)$, o crescimento pessoal ( $1 \mathrm{I}, 17 \%)$, a formação profissional $(10,61 \%)$, a qualidade do curso
$(8,94 \%)$ e a qualidade da universidade $(6,14 \%)$. Em um estudo com 39I universitários em meio de curso oriundos de várias áreas de formação, Bardagi, Lassance e Paradiso (2003) investigaram os níveis de satisfação com a escolha profissional, as avaliações relativas ao mercado de trabalho e a necessidade de intervenções em orientação profissional percebida pelos alunos. Como resultado, relataram que a percepção de identificação pessoal com o curso foi descrita como a principal fonte de satisfação; além disso, os alunos satisfeitos tendiam a apresentar uma avaliação mais otimista das possibilidades do mercado de trabalho, relativizar as eventuais dificuldades para obtenção de resultados e apresentar um maior bemestar psicológico.

O papel das atividades acadêmicas além da freqüência às aulas (por exemplo, monitoria, estágios, iniciação científica, participação em eventos, etc) e do trabalho para a satisfação é crescentemente significativo nas pesquisas. A inserção em atividades acadêmicas costuma ser associada à maior identidade profissional percebida. Bardagi e colaboradores (2003) observaram que os alunos que tinham pelo menos uma atividade no curso eram mais satisfeitos do que aqueles que não possuíam atividades. Brooks, Cornelius, Greenfield e Joseph (1995) descrevem a importância da atividade de estágio como exercício do papel profissional e fortalecimento da relação com a carreira, além de facilitar o estabelecimento de metas profissionais realistas. Fior e Mercuri (2004) e Teixeira e Gomes (2004), ao avaliarem o impacto de atividades não-obrigatórias sobre a formação superior, descrevem resultados positivos destas atividades sobre as aprendizagens, o desenvolvimento vocacional e o desenvolvimento pessoal, desde que relacionadas à área de formação.

Percepções quanto ao mercado de trabalho e às possibilidades de inserção também parecem ser fundamentais para a satisfação. Os fatores externos dominam as preocupações de adolescentes antes da tomada de decisão (Lassance, 1997) e também de estudantes universitários e profissionais já inseridos no mercado (Cattani, 1996). Em um estudo que avaliou as expectativas de estudantes formandos sobre a saída da universidade, Teixeira e Gomes (2004) 
identificaram que a percepção de mercado desfavorável está associada a um menor grau de decisão de carreira e a percepção de mercado favorável a um maior otimismo quanto à inserção e obtenção de resultados. Essa percepção do mercado de trabalho difícil como a principal barreira de carreira é identificada tanto nas mulheres quanto nos homens (Luzzo, 1995; McWhirter, 1997). Em um artigo teórico que discute o papel das barreiras percebidas no desenvolvimento vocacional dos indivíduos e relaciona a percepção de barreiras com o estilo atribucional, Albert e Luzzo (1999) descrevem resultados de pesquisa apontando um volume substancial de barreiras de carreira percebidas por estudantes universitários e de Ensino Médio; no entanto, um estilo atribucional caracterizado por uma maior internalidade seria favorecedor de um melhor ajustamento à escolha e à carreira como um todo. Com relação às diferenças de gênero, as mulheres parecem perceber um maior número de barreiras para obtenção de metas de carreira do que os homens, especialmente em função do conflito culturalmente estabelecido entre o papel profissional e, por exemplo, o cuidado com os filhos (McWhirter, 1997; Strey, González, Martínez \& Carrasco, 1995).

Há, também, por parte dos estudantes, uma grande confusão entre a profissão escolhida e as características do curso e do mercado. O descontentamento com as condições do ensino e da inserção é generalizado para um descontentamento com a profissão de uma forma geral (Bardagi \& cols., 2003).

Em especial, o momento do curso parece ser um importante aspecto do desenvolvimento vocacional de universitários. Ao coordenar uma pesquisa longitudinal realizada com estudantes universitários desde seu ingresso no curso até a proximidade da formatura, Lassance (1997) salienta que existem etapas distintas na relação entre o aluno, a escolha e o curso. A primeira fase seria de entusiasmo pela vitória no vestibular, o ingresso na universidade e a expectativa com o início da formação. Uma fase seguinte marcaria a decepção com o curso, os professores, a instituição, as condições de aprendizagem, e englobaria preocupações sobre uma possível nova escolha profissional. O terceiro momento mostra um aumento pelo interesse na continuidade do curso, fase em que o engajamento em atividades acadêmicas é fundamental para a satisfação e o comprometimento. $O$ quarto e último momento caracterizam-se pela proximidade do término do curso, quando a qualidade das atividades exercidas e a avaliação da formação produzem expectativas quanto à atuação profissional. Outros estudos foram realizados também contribuindo com informações acreca dessas etapas (Brooks \& cols., 1995; Göks \& Lassance, 1995, 1997; Fior \& Mercuri, 2004, dentre outros).

No período final da formação, contexto de análise deste trabalho, o sentimento de responsabilidade dos alunos aumenta e predominam os sinais de impotência e a sensação de pouco saber para enfrentar o mundo do trabalho, conforme apontado por Melo-Siva \& Reis (1997) ao descreverem uma experiência com estudantes de último ano do curso de Psicologia. Com isso, os questionamentos costumam refletir o grande medo de sair da faculdade, perder os vínculos estabelecidos e, assim, os alunos costumam se sentir sozinhos, isolados, incapazes de fazer a transição entre ser estudante e ser profissional. (Teixeira \& Gomes, 2004; Uvaldo, 1995).

Esta insegurança dos alunos em final de curso frente ao início da atividade profissional faz com que os alunos refiram a necessidade de auxílio à inserção no mercado de trabalho, e sintam-se especialmente interessados em ferramentas instrumentalizadoras, como estratégias de busca de emprego, oficinas de currículo etc. Em um estudo com formandos americanos, Werbel (2000) encontrou associação positiva entre a intensidade da procura de emprego e a inserção no mercado de trabalho e aponta que a universidade deveria realmente reconhecer a importância de desenvolver nos alunos habilidades para a busca de trabalho. Em oposição ao sentimento geral de insegurança e pessimismo dos estudantes em final de curso, Teixeira e Gomes (2004) observaram um otimismo frente à inserção no mercado de trabalho. Para os autores, este resultado pode indicar um mecanismo regulador que minimiza as dificuldades a fim de manter a auto-estima e a motivação para a transição. 
Como apontaram Kalakoski e Nurmi (1998), nos períodos de transição acadêmica são encontrados os maiores conflitos vocacionais e aumentam as preocupações e o comprometimento com escolhas acadêmicas e de carreira. A conclusão do curso universitário e o momento da inserção no mercado de trabalho pressupõem, assim, períodos propícios para o surgimento de preocupações relativas à escolha, configurando-se, então, momentos cruciais para a investigação científica. O período universitário, ainda, caracteriza uma etapa exploratória, na qual o jovem especifica sua identidade (Erikson, 1976) e, para uma parte destes indivíduos, a conclusão do curso superior pode ser considerada uma reedição da crise vocacional da adolescência (Bohoslavsky, 1977, 1998). Entretanto, observam-se, no Brasil, uma carência de estudos que identifiquem características vocacionais e necessidades de intervenção com a população universitária em final de curso.

Assim, um estudo exploratório iniciado com universitários em meio de curso (Bardagi \& cols., 2003) e formandos, teve por finalidade conhecer as trajetórias acadêmicas dos estudantes e sua percepção de satisfação com a escolha profissional. O presente artigo apresenta os resultados relativos ao grupo de formandos, cujos dados enfatizaram ainda a percepção de dificuldades de inserção no mercado de trabalho e o levantamento de interesses quanto a processos de orientação profissional. Com isso, espera-se conhecer as necessidades dos estudantes em conclusão de curso frente ao momento de transição entre a Universidade e o mundo do trabalho, com o propósito de fornecer maiores subsídios para a compreensão da problemática vocacional e investigar aspectos relevantes a serem considerados na formulação de propostas de intervenção com esta população.

\section{Método}

\section{Participantes}

Participaram deste estudo 340 formandos (56,6\% homens) de 16 cursos da UFRGS, com idade média de 25 anos $(D P=5,35)$. Destes, 36,8\% eram de cursos da área de Humanas, $24,7 \%$ da área de
Biológicas, 23,2\% da área de Exatas e 15,3\% da área de Letras e Artes.

\section{Instrumento}

\section{Questionário sobre Satisfação Profissional}

O Questionário sobre Satisfação Profissional semiestruturado (em anexo) é composto por 22 itens objetivos e 4 questões abertas. Os itens objetivos referem-se a questões sócio-demográficas, participação em atividades acadêmicas, nível de satisfação com a escolha profissional, identificação de áreas de interesse, percepção de dificuldades de inserção no mercado de trabalho, interesse por processos de Orientação Profissional e expectativas quanto ao início da atuação profissional. Os itens discursivos referem-se à justificativa da resposta ao item I 2 (satisfação com a escolha), justificativa para a resposta ao item 13 (pretender ou não seguir carreira na profissão escolhida), identificação de dificuldades de inserção e sentimentos e expectativas com relação à atuação profissional. Os três últimos tópicos foram acrescentados ao instrumento utilizado na investigação com alunos em meio de curso publicado anteriormente (Bardagi \& cols., 2003). Os itens foram criados a partir de variáveis importantes para o desenvolvimento vocacional citadas pela literatura e 3 profissionais que atuam na área da Orientação Profissional serviram como juízes para assegurar a validade aparente do instrumento. Este procedimento compreendeu a leitura dos itens e sugestões quanto ao rapport e modificações na linguagem do material. $A$ análise da validade aparente assegura a verificação da relevância e plausibilidade do instrumento em relação aos objetivos do estudo (Anastasi \& Urbina, 2000). Após a análise da validade aparente, um estudo piloto, realizado com 61 estudantes universitários, permitiu a definição dos procedimentos finais de rapport e aplicação.

\section{Procedimento}

Para a coleta dos dados na amostra final, foi realizada aplicação coletiva do instrumento em sala de aula. Cada aplicação foi precedida de uma explicação dos objetivos do estudo e foram disponibilizadas aos alunos informações e encaminhamentos, quando 
necessário ou solicitado. As unidades de ensino foram contatadas e indicaram os melhores dias e horários para realização da coleta. A participação dos estudantes foi voluntária com assinatura do Consentimento Livre e Esclarecido.

\section{Resultados}

Os dados objetivos foram tratados estatisticamente, principalmente através do levantamento de freqüências e testes de associação Qui-quadrado. As quatro respostas discursivas foram submetidas a uma análise de conteúdo (Bardin, 1977). Após a leitura inicial do conjunto das respostas a cada uma das questões, para estabelecer um primeiro contato com o material, uma exploração dos dados das respostas foi feita, decodificando-as a fim de escolher as unidades de sentido. Em seguida, a categorização destes elementos e o agrupamento das unidades de sentido de acordo com o que tinham de comum entre si foram efetuados. A partir do agrupamento das unidades de sentido, chegou-se a categorias emergentes não exclusivas, seguindo um critério de consenso entre 4 juízes. Cada resposta discursiva gerou um grupo de categorias.

Os resultados serão apresentados por temas, incluindo-se as respostas objetivas (tratadas estatisticamente) e as categorias que emergiram das respostas discursivas, quando for 0 caso.

\section{Participação em Atividades Acadêmicas e Satisfação com a Escolha Profissional}

A maioria dos alunos (56,5\%) participa de atividades relacionadas ao curso - monitoria $(9,5 \%)$, iniciação científica $(26,3)$ e estágio $(30,5 \%)$, sendo que muitos alunos têm mais de uma destas atividades. Quanto aos níveis de satisfação com a escolha profissional $35,5 \%$ estão muito satisfeitos, $53,1 \%$ estão satisfeitos, $10,1 \%$ estão pouco satisfeitos e I, $2 \%$ estão insatisfeitos. Não houve associação entre sexo e ter ou não atividade no curso. Muitos estudantes relatam estarem envolvidos com outras atividades externas remuneradas $(45,6 \%)$. Dentre estes, somente $35,4 \%$ estão envolvidos com atividades de alguma forma relacionadas à profissão. Alunos da área de Letras e Artes possuem mais atividades externas remuneradas do que alunos das outras áreas $\left(\chi^{2}=\right.$ I2,59; $g . I=3 ; p<0,0 \mathrm{I})$. Os alunos envolvidos em pelo menos uma atividade acadêmica relatam com maior freqüência estarem muito satisfeitos com a escolha profissional do que alunos que não possuem atividades acadêmicas $\left(\chi^{2}=26,06 ; g . l=3 ; p<0,00 I\right)$. Não houve associação entre nível de satisfação com a escolha e área de formação ou sexo.

Ao se analisarem as justificativas para o nível de satisfação com a escolha profissional, os participantes foram divididos em dois grupos, a saber: muito satisfeitos e satisfeitos (Grupo I) e pouco satisfeitos e insatisfeitos (Grupo 2). As respostas à questão aberta que justificava a satisfação ou insatisfação com a escolha profissional foram agrupadas em categorias emergentes. As mesmas categorias apareceram para os dois grupos, com conotações diferentes, exceto a categoria experiência, que só apareceu nas respostas do Grupo I. A Tabela I mostra as freqüências em que as respostas de cada categoria aparecem nos dois grupos. As justificativas para o nível de satisfação com a escolha profissional foram agrupadas nas seguintes categorias:

Tabela I. Razões para o Nível de Satisfação com a Escolha Profissional (em \%)

\begin{tabular}{lcc}
\hline \multicolumn{1}{c}{ Escolha Profissional } & $\begin{array}{c}\text { G1- Muito Satisfeitos e } \\
\text { Satisfeitos }\end{array}$ & $\begin{array}{c}\text { G2- Pouco Satisfeitos ou } \\
\text { Insatisfeitos }\end{array}$ \\
\hline Pessoal & 57,6 & 13,2 \\
Mercado & 13,9 & 57,9 \\
Profissão & 13,9 & 15,8 \\
Curso & 9,9 & 13,2 \\
Experiência & 4,5 & - \\
\hline
\end{tabular}




\section{Pessoal}

Afirmações relativas ao interesse, realização e identificação com a profissão e atividades inerentes a ela, motivação e sentimento de adequação. Ex: “Me encontrei profissionalmente dando aulas. Me realizo ensinando" (GI); "Não é o que eu queria para mim" (G2).

\section{Mercado de trabalho}

Afirmações relativas à percepção do campo de trabalho, emprego, remuneração, concorrência. Ex: "A perspectiva de colocação no mercado é boa" (GI); "O mercado está saturado e não oferece grandes atrativos financeiros" (G2).

\section{Profissão}

Afirmações relativas ao reconhecimento social da profissão e às atividades inerentes à mesma. Ex: " $A$ profissão permite a atuação do farmacêutico em inúmeras áreas, sem falar no cuidado com a saúde da população, que é essencial” (GI); "A classe não está organizada. A profissão de músico não é regulamentada” (G2).

\section{Curso}

Afirmações relativas à qualidade e atividades do curso, professores, disciplinas. Ex: "Eu aprendi muitas coisas teórico-práticas para auxiliar o processo empresarial" (GI); "Não senti que a formação seja suficiente" (G2);

Experiência: Afirmações relativas ao contato já existente com a prática profissional e a área de formação. Ex: "Tive experiência em sala de aula e pude ver que acertei em cheio na escolha do curso" (GI).

\section{Inserção no Mercado de Trabalho e Orientação Profissional}

Dos participantes, 95,2\% pretendem seguir carreira na profissão e $57,7 \%$ identificam dificuldades de inserção no mercado de trabalho. A maioria dos estudantes pouco satisfeitos e insatisfeitos refere ter planos de trabalhar na área (72,2\%), apesar do descontentamento. Não houve associação entre possuir outra atividade remunerada ou perceber dificuldades no mercado e seguir carreira na profissão. Aqueles que possuem pelo menos uma atividade acadêmica relacionada ao curso referem mais vontade de seguir carreira na profissão do que aqueles sem envolvimento nessas atividades $\left(\chi^{2}=4,55 ; g . l=I ; p<\right.$ $0,05)$.

As mulheres apontam significativamente mais dificuldades de inserção do que os homens $\left(\chi^{2}=19,9\right.$; $g . I=I ; p<0,00 I)$. Ainda, aqueles alunos que se descrevem muito satisfeitos ou satisfeitos com sua escolha referem menos dificuldades de inserção no mercado do que os alunos pouco satisfeitos ou insatisfeitos $\left(\chi^{2}=10,2 ; g . l=3 ; p<0,05\right)$.

A Tabela 2 apresenta as freqüências de aparecimento das respostas relativas aos tipos de dificuldades percebidas para inserção no mercado. As categorias foram estabelecidas da seguinte maneira:

\section{Mercado}

Afirmações relativas à percepção difícil do campo de trabalho, oportunidades de emprego, remuneração, concorrência. Ex.: "Mercado saturado, muita concorrência e pouca oferta" (GI): Afirmações relativas à falta de identificação, capacidades ou

Tabela 2. Dificuldades Percebidas para Inserção no Mercado de Trabalho (em \%)

\begin{tabular}{lcc}
\hline Escolha Profissional & $\begin{array}{c}\text { G1- Muito Satisfeitos e } \\
\text { Satisfeitos }\end{array}$ & $\begin{array}{c}\text { G2- Pouco Satisfeitos ou } \\
\text { Insatisfeitos }\end{array}$ \\
\hline Mercado & 61,2 & 82,1 \\
Pessoal & 12,2 & 3,6 \\
Experiência & 10,3 & 10,7 \\
Profissão & 4,5 & - \\
Invest. Financeiro & 3,8 & - \\
Discriminação & - & 3,6 \\
Outros & 7,7 & - \\
\hline
\end{tabular}


habilidades pessoais para inserção no mercado. Ex.: "Pouca identificação com o curso" (G2).

\section{Experiência}

Afirmações relativas à percepção de experiência insuficiente. "Entrar no mercado com pouca experiência" (G2).

\section{Profissão}

Afirmações relativas à desvalorização e falta de regulamentação da profissão. Ex.: "Desvalorização da minha profissão não ajuda na hora de conseguir emprego" (GI)

Investimento Financeiro: Afirmações relativas ao capital necessário para o início de carreira (local, equipamentos,...). Ex.: "Não gostaria de ser empregada por muito tempo, mas os custos de um laboratório próprio são altos" (GI).

\section{Discriminação}

Afirmações relativas ao preconceito de idade, cor, sexo. Ex.: "Há preconceito pela idade" (G2). percebem dificuldades de inserção $\left(\chi^{2}=13,2 ;\right.$ g. $I=I$; $p<0,00$ I).

Quanto às respostas à questão aberta que investigou as expectativas relativas ao início da atividade profissional, a Tabela 3 mostra as freqüências de respostas nos dois grupos. As respostas dos alunos foram agrupadas nas seguintes categorias:

\section{Realização do Projeto Profissional}

Considerações sobre planos de atividades, estruturação de carreira, busca de maior aperfeiçoamento. Ex.: "Pretendo trabalhar na formação de professores de matemática, relacionando com informática na educação, além de fazer pós-graduação nesta área" (GI).

\section{Expectativas Positivas}

Considerações sobre as possibilidades de sucesso profissional, rápida inserção no mercado de trabalho, boa remuneração e bom desempenho. Ex.: "São as melhores possíveis, apesar das dificuldades

Tabela 3. Sentimentos e Expectativas quanto à Futura Atividade Profissional (em \%)

\begin{tabular}{lcc}
\hline \multicolumn{1}{c}{ Sentimentos e expectativas } & $\begin{array}{c}\text { G1 - Muito Satisfeitos e } \\
\text { Satisfeitos }\end{array}$ & $\begin{array}{c}\text { G2 - Pouco Satisfeitos e } \\
\text { Insatisfeitos }\end{array}$ \\
\hline Realização Projeto Profissional & 13,4 & 6,7 \\
Expectativas Positivas & 51,0 & 12,3 \\
Medos e Angústias & 34,2 & 22,0 \\
Negação & 1,4 & - \\
Expectativas Negativas & - & 30,0 \\
Frustração & - & 30,0 \\
\hline
\end{tabular}

Em relação a processos de Orientação Profissional, os mais citados foram instrumentalização para busca de emprego (47\%), auxílio na elaboração de projetos profissionais (39\%) e re-orientação de carreira $(13,8 \%)$, sendo possível optar por mais de um dos processos. Não foram significativas as relações entre busca por processos de Orientação Profissional e sexo, nível de satisfação com o curso ou identificar áreas em que gostaria de atuar. Aqueles alunos que percebem maiores dificuldades de inserção no mercado se interessam mais por processos de Orientação Profissional do que alunos que não e obstáculos que a profissão oferece, é o que eu gosto de fazer e espero contribuir de alguma forma para que a profissão seja mais valorizada através do meu trabalho" (GI).

\section{Medos e Angústias}

Considerações sobre sentimentos de insegurança, ansiedade, apreensão e dúvida quanto à atividade futura. Ex.: "Tenho vontade de desenvolver alguns projetos(...), mas tenho receio da rejeição e de não saber o que fazer depois. Também penso em procurar um emprego e tenho medo de não conseguir " (GI). 


\section{Negação}

Recusa em descrever sentimentos e expectativas quanto ao início da atividade profissional. Ex.: "Ainda não parei para realmente pensar no assunto" (GI).

\section{Expectativas Negativas}

Expectativas de dificuldades de inserção no mercado, baixa remuneração, falta de competência e pouca possibilidade de sucesso profissional. Ex.: "Encontro-me relativamente desestimulado(...). O que chamam de abertura de novas oportunidades eu chamaria de reescravização profissional" (G2).

\section{Frustração}

Sentimento de descontentamento com a formação, a escolha profissional, o futuro ambiente de trabalho e o rumo da carreira. Ex.: "Frustração e nenhuma perspectiva agradável” (G2).

\section{Discussão}

A fim de entender possíveis relações de satisfaçãoinsatisfação no final do curso universitário e o processo de inserção no mercado de trabalho, investigaram-se a trajetória acadêmica, as dificuldades percebidas para o início da carreira e a percepção do benefício da Orientação Profissional. De forma geral, os achados do estudo corroboram a literatura no que diz respeito às dificuldades e incertezas da população universitária tanto em relação à escolha profissional quanto à entrada no mundo do trabalho, apontando que para uma parte destes indivíduos a conclusão do curso superior seria uma reedição das crises vocacionais anteriores (Kalakosky \& Nurmi, 1998; Melo-Silva \& Reis, 1997; Uvaldo, 1995). Além disso, a partir do relato dos próprios estudantes, observou-se à importância de processos de intervenção que possam dar suporte às necessidades apontadas pelos participantes.

Os resultados deste estudo indicam, assim como no estudo com alunos em meio de curso (Bardagi \& cols., 2003), que possuir pelo menos uma atividade acadêmica é um aspecto relacionado à maior satisfação com a escolha profissional. Da mesma forma, possuir atividade ligada ao curso também direciona os estudantes a relatarem mais vontade de seguir carreira na profissão. Aqueles que participam de atividades ligadas à profissão escolhida provavelmente têm informações mais realistas e concretas, o que pode ratificar a escolha, evidenciando características, habilidades ou identificações pessoais que apóiam a decisão de entrar no campo de trabalho, como apontam Brooks e colaboradores (1995), Fior e Mercuri (2004) e Lassance (1997). Estes dados ressaltam a importância de um planejamento curricular e de uma política de investimento na formação dos alunos, no sentido de proporcionar aos mesmos, o mais cedo possível, um contato com a realidade profissional.

Muitos estudantes relataram estarem envolvidos com atividades remuneradas fora de seus cursos. Este fato pode revelar tanto a presença de múltiplos interesses quanto as exigências impostas pelas condições sócio-econômicas durante a formação acadêmica, esperando-se envolvimento e investimento emocional, familiar e financeiro. $O$ aluno que necessita contribuir para a renda familiar, por exemplo, provavelmente irá priorizar a obtenção de um emprego e se envolverá menos com as atividades do curso. O maior número de alunos com atividades remuneradas fora de seus cursos foi encontrado na área de Letras e Artes. Este dado pode ser explicado pelo fato desses alunos possuírem a maior média de idade fazendo com que, muitas vezes, optem por continuar suas atividades profissionais anteriores à entrada na Universidade. Pode-se pensar, ainda, que estes cursos não oferecem atividades acadêmicas suficientes e/ou atraentes para seus alunos, levandoos a procurar atividades remuneradas fora de sua área de atuação. Estudos anteriores apontam que o trabalho integral ou parcial fora do campus, e que não está associado à formação, tende a ter um impacto negativo sobre o aluno, o comprometimento com a escolha e a satisfação (Fior \& Mercuri, 2004; Göks \& Lassance, 1995, 1997), aumentando a preocupação com a integração e o desenvolvimento vocacional destes estudantes.

Os alunos justificaram estar muito satisfeitos ou satisfeitos com a escolha profissional, na maioria das vezes, por razões de ordem pessoal (realização, motivação, sentimento de adequação, entre outras). Por outro lado, a maioria dos alunos pouco satisfeitos 
ou insatisfeitos com a escolha profissional apresentou justificativas referentes a questões de mercado (oportunidades de emprego, remuneração, concorrência, entre outras). Cada indivíduo tende a atribuir aos fatos causas internas ou externas e levar suas habilidades pessoais, necessidades, valores e metas para a profissão, fazendo com que as atividades profissionais tidas como interessantes sejam aquelas que ofereçam numerosas oportunidades para criatividade e realização (Super, Savickas \& Super, 1996). Este resultado é semelhante ao obtido com alunos em meio de curso (Bardagi \& cols., 2003) e também em outros estudos (Pachane, 2004; Teixeira \& Gomes, 2004) que apontam a identificação pessoal como condição necessária para a satisfação, mas a presença do mercado de trabalho como um forte mediador das relações entre o aluno e o curso.

O mercado de trabalho constitui-se tema central quando se trata da percepção de dificuldades para inserção profissional tanto entre os alunos muito satisfeitos e satisfeitos quanto pouco satisfeitos e insatisfeitos com a escolha. Em ambos os grupos, a tendência de queda do trabalho formal, a maior competição entre os profissionais, a maior exigência de qualificação, a necessidade de experiência, entre outros aspectos, foram apontados, refletindo um conhecimento da realidade atual do mundo do trabalho. Entretanto, as dificuldades do mercado de trabalho perdem força para aqueles indivíduos que justificam seu nível de satisfação por aspectos internos. Estes indivíduos, por estarem pessoalmente mais identificados com a profissão, apresentam maior disposição para lidar com as condições do mercado de trabalho e também assumem uma postura de maior responsabilidade sobre a sua inserção profissional. Por outro lado, alguns estudantes supervalorizam as condições do mercado de trabalho e tornam-se desmotivados e menos interessados pela própria profissão ao perceberem dificuldades de inserção profissional.

Os resultados deste estudo demonstram que os formandos muito satisfeitos ou satisfeitos parecem estar conseguindo integrar os próprios interesses com o mundo profissional no qual estão prestes a se inserir e com o qual se depararam durante os anos de formação. No caso dos alunos pouco satisfeitos ou insatisfeitos, a realidade externa adquire um peso maior direcionando negativamente seu posicionamento frente à satisfação com a escolha. Alguns autores apontam a internalidade favorecendo uma ocupação na área desejada, um maior nível de maturidade de carreira, maior engajamento em atividades exploratórias e um maior nível de decisão (Albert \& Luzzo, 1999; Luzzo, 1995). Em contraponto, a atribuição de causalidade externa é vista como barreira para o desenvolvimento vocacional (Albert \& Luzzo, 1999). Nesse caso, o indivíduo atribui ao mercado, sorte ou acaso as causas de seu sucesso ou fracasso profissional. Futuras pesquisas, investigando a relação entre locus de controle e desenvolvimento vocacional, podem levar a uma maior compreensão de aspectos como satisfação com a escolha, inserção no mercado de trabalho, entre outros.

De uma forma geral, a maioria dos alunos relatou perceber dificuldades de inserção profissional, mas entre os alunos muito satisfeitos ou satisfeitos esta percepção é menor. Considerando-se que a satisfação positiva com a escolha baseia-se, principalmente, em aspectos pessoais, podemos supor que estes alunos percebem em si melhores condições para lidar com o momento da inserção profissional (Super, Savickas \& Super, 1996). Entretanto, a maioria dos participantes tem planos de seguir carreira na profissão não sendo, necessariamente, afetados pelo nível de satisfação com a escolha. Mesmo aqueles alunos pouco satisfeitos ou insatisfeitos, e que apontam inúmeras dificuldades no mercado de trabalho, manifestam intenção de atuar na profissão, demonstrando que aspectos como os anos dispensados à formação, o investimento financeiro, as expectativas familiares e sociais, entre outros, pode ter uma maior relevância nesta decisão.

A menor percepção das dificuldades observados entre os estudantes muito satisfeitos e satisfeitos pode estar correlacionada também com níveis positivos de auto-estima e autoconfiança associados à satisfação com a escolha profissional (Albert \& Luzzo, 1999; Luzzo, 1995). No entanto, é preocupante imaginar que um número grande de profissionais estão se 
dispondo a exercer atividades com as quais não se identificam. É possível pensar que talvez, com a existência de processos de aconselhamento de carreira, estes estudantes conseguissem identificar novas formas de se relacionar com a profissão ou realizar transições e mudanças de carreira que propiciassem uma maior realização pessoal. Nesse sentido, a existência de redes de apoio aos estudantes, dentro do contexto universitário, que estejam focadas na discussão dos projetos profissionais futuros tornase fundamental, tanto para a diminuição dos índices de insatisfação quanto para o auxílio em processos de mudanças profissionais.

Quanto a diferenças de gênero, as mulheres apresentaram uma maior tendência a relatar dificuldades percebidas para inserção no mercado de trabalho. Este achado vem ao encontro dos dados disponíveis na literatura que mostram que as mulheres citam mais barreiras percebidas para 0 desenvolvimento de carreira do que os homens e que o papel do trabalho para elas concorre com outros papéis - conjugal, materno etc, resultando em diferenças qualitativas no comprometimento com o trabalho em relação aos homens (Lassance, 1997; Luzzo, 1995; McWhirter, 1997; Strey \& cols., 1995). A questão do gênero seria, então, uma variável significativa na construção e avaliação do projeto profissional. Estudos futuros, especialmente de caráter qualitativo poderão auxiliar no entendimento do desenvolvimento de carreira feminino. De forma geral, a maior percepção de barreiras pode servir como força motivadora para o planejamento cuidadoso e a exploração de carreira e a menor percepção de dificuldades pode levar a uma diminuição da motivação para o planejamento e o estabelecimento de metas. Cabe aos orientadores, então, auxiliar os profissionais a utilizar as barreiras percebidas como forças motivacionais no desenvolvimento de carreira.

Quanto ao relato das expectativas relativas à futura atividade profissional, aqueles alunos mais pessoalmente envolvidos com a profissão apresentaram, em sua maioria, expectativas positivas, além dos medos e angústias, sentimentos esperados em momentos de transição como este (Melo-Silva \& Reis, 1997; Teixeira \& Gomes, 2004). Já os estudantes pouco satisfeitos ou insatisfeitos com a escolha profissional apresentaram expectativas negativas e de frustração somadas à ansiedade deste momento. Talvez uma maior identificação com a profissão auxilie na relativização das dificuldades do mercado e permita melhores condições de lidar com ambigüidades e conflitos inerentes à transição universidade-trabalho. Aqui, novamente, vê-se a necessidade de que os cursos propiciem espaços, até hoje pouco comuns, de discussão desta transição, como forma de fortalecer a auto-eficácia para tomada de decisão e preparar melhor o aluno formando para os desafios do mundo do trabalho (Werbel, 2000).

Uma das principais necessidades manifestadas pelos estudantes é a instrumentalização para a busca de emprego, e envolve desde a organização do currículo até a preparação para entrevistas de seleção. Esse resultado confirma os achados de um estudo anterior (Werbel, 2000), que mostrou a necessidade desse tipo de intervenção entre os formandos. Essa demanda por intervenções mais pontuais pode ser um reflexo dos sentimentos de insegurança associados à antecipação das dificuldades de inserção no mercado de trabalho, observados nos alunos no período final da graduação (Melo-Silva \& Reis, 1997; Teixeira \& Gomes, 2004; Uvaldo, 1995). O conceito de trabalho, neste momento da carreira, parece intrinsecamente ligado à obtenção de um lugar no mundo profissional (Lassance, 1997).

De forma geral, este trabalho teve por objetivo investigar os estudantes formandos a fim de identificar as características e necessidades dos mesmos em relação ao desenvolvimento vocacional e à inserção no mundo profissional. A escassez de estudos anteriores com essa população evidenciava a necessidade de um levantamento preliminar e geral de dados que pudessem servir como ponto de partida para futuras investigações e eventuais propostas de intervenção. Os resultados obtidos permitiram reflexões importantes sobre a trajetória acadêmica, a satisfação com a escolha profissional e a transição universidade-trabalho.

A partir destes resultados, novas investigações acerca de relações específicas entre satisfação com a escolha e características individuais, aspectos sócio- 
econômicos, entre outros, são importantes para uma melhor compreensão tanto de como os estudantes vivenciam sua escolha profissional no momento final da formação acadêmica quanto de como o orientador profissional pode contribuir com eficácia no processo da escolha de uma profissão e no auxílio do planejamento de carreira e inserção no mercado de trabalho. Além disso, constataram-se a necessidade de estudos longitudinais que acompanhem o desenvolvimento dos estudantes ao longo do processo de formação, estudos comparativos entre alunos de diferentes universidades, públicas e privadas, e estudos qualitativos que permitam uma abordagem mais compreensiva do desenvolvimento vocacional de estudantes universitários em final de curso.

\section{Referências}

Albert, K. A., \& Luzzo, D. A. (1999). The role of perceived barriers in career development: a social cognitive perspective. Journal of Counseling and Development, 77(4), 43I-436.

Anastasi, A., \& Urbina, S. (2000). Testagem psicológica. Porto Alegre,RS: Artmed.

Bardagi, M. P., Lassance, M. C. P., \& Paradiso, A C. (2003). Trajetória acadêmica e satisfação com a escolha profissional de universitários em meio de curso. Revista Brasileira de Orientação Profissional, 4(I), I53-166.

Bardin, L. (1977). Análise de conteúdo. Lisboa: Edições 70.

Bohoslavsky, R. (1998). Orientação vocacional - a estratégia clínica. Originalmente publicado em 1977. São Paulo,SP: Martins Fontes.

Brooks, L., Cornelius, A., Greenfield, E., \& Joseph, R. (1995). The relation of career- related work or internship experiences to the career development of college seniors. Journal of Vocational Behavior, 46, 332-49.

Cattani, A. D. (1996). Trabalho e autonomia. Petrópolis,RJ: Vozes.

Erikson, E. (1976). Identidade, juventude e crise. Rio de Janeiro,RJ: Zahar.

Fior, C. A., \& Mercuri, E. (2004). Formação universitária: o impacto das atividades não-obrigatórias. Em: E. Mercuri \& S. A. J. Polydoro (Orgs.), Estudante universitário: características e experiências de formação. (pp. 129-154). São Paulo,SP: Cabral Editora e Livraria Universitária.

Göks, A., \& Lassance, M. C. P. (1995). A formação da identidade profissional em estudantes universitários - Pensando a prática profissional (pp.255). In Anais 7. VII Salão de Iniciação Científica da UFRGS, 1995, Porto Alegre, RS: UFRGS.

Göks, A., \& Lassance, M. C. P. (1997). Formação da identidade profissional em estudantes universitários: as trajetórias acadêmicas (pp.369). In Anais 9. IX Salão de Iniciação Científica da UFRGS, 1997, Porto Alegre, RS: UFRGS.

Kalakoski, V., \& Nurmi, J. E. (1998). Identity and educational transitions: age differences in adolescent exploration and commitment related to education, occupation and family. Journal of Research on Adolescence, 8(I), 29-47.

Lassance, M. C. P. (1997). A orientação profissional e a globalização da economia. Revista da Abop, I(I), 7I-80.

Luzzo, D. A. (1995). Gender differences in college student's career maturity and perceived barriers in career development. Journal of Counseling and Development, 73(, $319-22$.

Mcwhirter, E. H. (1997). Perceived barriers to education and career: ethnic and gender differences. Journal of Vocational Behavior, 50(I), 124-40.

Melo-Silva, L. L., \& Reis, V. A. B. (1997). A identidade profissional em estudantes do curso de psicologia: intervenção através da técnica de grupo operativo (pp. 57-65). Em: Resumos, Associação Brasileira de Orientadores Profissionais (Org.), Anais do III Simpósio Brasileiro de Orientadores Profissionais, 1997, Canoas, RS.

Pizzinato, A., Boeckel, M. G., Dellazzana, L. L., Coral, R. V., \& Sarriera, J. C. (200I). Projetos vitais, ocupacionais e profissionais em adolescentes desempregados (pp. 373383). Em: Resumos, Associação Brasileira de Orientadores Profissionais (Org.), Anais do IV Simpósio Brasileiro de Orientação Vocacional e Ocupacional, 200I, São Paulo,SP.

Pachane, G. G. (2004). A experiência universitária e sua contribuição ao desenvolvimento pessoal do aluno. Em: $\mathrm{E}$. Mercuri \& S. A. J. Polydoro (Orgs.), Estudante universitário: Características e experiências de formação. (pp.155-186). São Paulo, SP: Cabral Ed. e Livraria Universitária.

Ribeiro, M. A. (2003). Demandas em orientação profissional: um estudo exploratório em escolas públicas. Revista Brasileira de Orientação Profissional, 4(I/2), |4I-I5I. 
Soares, D. H. P. (2002). A escolha profissional: do jovem ao adulto. São Paulo, SP: Summus.

Sparta, M. (2003). A exploração e a indecisão vocacionais em adolescentes no contexto educacional brasileiro. Dissertação de Mestrado. Universidade Federal do Rio Grande do Sul, Porto Alegre.

Strey, M. N., González, A. M., Martínez, J. L., \& Carrasco, J. M. M. (1995). A construção do projeto profissional na mulher: estudo de alguns aspectos psicossociais. Psico, 26(I), 9-28.

Super, D. E., Savickas, M. L. \& Super, C. M. (1996). The lifespan, life-space approach to careers. Em: D. Brown \& L. Brooks (Orgs), Career choice and development. (pp. I 2 I178). San Francisco, CA: Jossey-Bass.
Teixeira, M. A. P., \& Gomes, W. B. (2004). Estou me formando...e agora? Reflexões e perspectivas de jovens formandos universitários. Revista Brasileira de Orientação Profissional, $5(I), 47-62$.

Uvaldo, M. C. C. (1995). Relação homem-trabalho: campo de estudo e atuação da orientação profissional. Em: A. M. B. Bock \& Cols., (Orgs.), A escolha profissional em questão. (pp. 215-237). São Paulo, SP: Casa do Psicólogo.

Werbel, J. D. (2000). Relationships among career exploration, job search intensity, and job search effectiveness in graduating college students. Journal of Vocational Behavior, 57, 379-94. 


\section{Anexo I \\ Universidade Federal do Rio Grande do Sul Instituto de Psicologia Serviço de Orientação Profissional}

Prezado(a) Estudante:

As informações obtidas a partir deste instrumento permitirão identificar características dos formandos visando à criação de um serviço de apoio à inserção no mercado de trabalho. Solicitamos que todas as perguntas sejam respondidas de forma mais completa possível. Gratos por sua colaboração.

I) Sexo: a. Masculino

b. Feminino

2) Idade:

3) Curso:

4) Ano que iniciou o curso:

5) Qual (is) atividade(s) você participa?

a. Monitoria

b. Bolsa de Iniciação Científica

c. Estágio Extra-Curricular

d. Nenhuma

6) Você possui outra atividade remunerada?

a. Sim. Qual?

b. Não

7) (Se a resposta $n^{\circ} 6$ foi afirmativa) A atividade exercida está relacionada ao curso?

a. Sim

b. Não

8) Quantas vezes você prestou vestibular?

9) Todas as tentativas foram para um mesmo curso?

a. Sim

b. Não

10) (Se a resposta $n^{\circ} 9$ foi negativa) Em que ano(s) e para que curso(s) você prestou vestibular?

Ano: [ ] Curso:

Ano: [ ] Curso:

Ano: [ ] Curso:

Ano: [ ] Curso:

II) Você está cursando, ou já concluiu, algum outro curso superior?

a. Sim. Qual?

b. Não

12) Como você se sente em relação à profissão escolhida?

a. Muito satisfeito

b. Satisfeito

c. Pouco Satisfeito

d. Insatisfeito

Justifique:

13) Você pretende seguir carreira nessa profissão?
a. Sim
b. Não
Justifique:

14) Você identifica alguma (s) área(s) na profissão em que gostaria de atuar?

a. Sim. Qual (is)?

b. Não

15) (Se a resposta $n^{\circ} 14$ foi afirmativa) Dentro dessa (s) área(s) de interesse, você identifica: 
- Atividade(s) que gostaria de fazer?

a. Sim. Qual (is)?

b. Não

- Local(is) em que você gostaria de trabalhar?

a. Sim. Qual (is)?

b. Não

16) (Se a resposta $n^{\circ} 14$ foi negativa) Que dificuldades você está encontrando para identificar a (s) área (s) na profissão em que gostaria de atuar?

17. Você tem planos de realizar outros cursos após a graduação?
a. Sim Qual(is)?
b. Não

18) Que dificuldades você identifica para a sua inserção no mercado de trabalho?

19) Em que termos de instrumentalização para busca de trabalho:

- Você sabe organizar seu currículo?
a. $\operatorname{Sim}$
b. Não

- Você se sente preparado para participar de processos seletivos?
a. Sim
b. Não

20) Você acredita que poderia se beneficiar de um Programa de Orientação Profissional para formandos?

a. Sim

b. Não

Justifique:

21) (Se a resposta $n^{\circ} \mathbf{2 0}$ foi afirmativa) Que opção(ões) atenderia(m) a seu(s) objetivo(s):
a. Reorientação Profissional
b. Construção de um projeto profissional
c. Instrumentalização para busca de trabalho
d. Outros:

22) Descreva seus sentimentos e expectativas quanto a sua futura atuação como profissional:

Recebido em: | 4//2/2005

Revisado em:26/02/2006

Aprovado em: 06/04/2006

\section{Sobre os autores}

Marúcia Bardagi (marucia.bardagi@gmail.com). Professora do curso de Psicologia da Universidade Luterana do Brasil - campus Santa Maria (RS) e dos cursos de especialização em Avaliação Psicológica e Orientação Profissional da Universidade Federal do Rio Grande do Sul.

Maria Célia Pacheco Lassance (mcpl@terra.com.br). Professora da Universidade Federal do Rio Grande do Sul, coordenadora do curso de especialização em Orientação Profissional.

Ioneide Almeida de Menezes( ioneidemenezes@hotmail.com) professora da Universidade Federal Rural de Pernanbuco. Funcionária do DETRAN/PE.

Ângela Carina Paradiso (paradiso@cpovo.net). Professora do curso de especialização em Orientação Profissional da Universidade Federal do Rio Grande do Sul.

Endereço para correspondência

Marúcia Bardagi

Rua Guilherme Alves, 450/204. Jardim Botânico

90680000. Porto Alegre - RS. 